\title{
Effectiveness of an Oral Health Education Program to Improve Mothers' Awareness of Natal Teeth: A Randomized Controlled Study
}

\author{
Olubunmi Olusola Bankole1,2(D), Folake Barakat Lawal $2,3,4$ (D)
}

\begin{abstract}
${ }^{1}$ Department of Child Oral Health, College of Medicine, University of Ibadan, Ibadan, Nigeria.
${ }^{2}$ Dental Centre, University College Hospital, Ibadan, Nigeria.

${ }^{3}$ Department of Periodontology and Community Dentistry, College of Medicine, University of Ibadan, Ibadan, Nigeria.

${ }^{4}$ Fellow, Consortium for Advanced Research Training in Africa (CARTA), Nairobi, Kenya.
\end{abstract}

Author to whom correspondence should be addressed: Dr. F.B. Lawal, Department of Periodontology and Community Dentistry, College of Medicine, University of Ibadan, PMB 5017, Ibadan, Nigeria. 200001. Phone: +2348023658988. Email: folakemilawal@yahoo.com.

Academic Editors: Alessandro Leite Cavalcanti and Wilton Wilney Nascimento Padilha

Received: 31 January 2020 / Accepted: 15 May 2020 / Published: 28 May 2020

How to cite this article: Bankole OO, Lawal FB. Effectiveness of an oral health education program to improve mothers' awareness of natal teeth: a randomized controlled study. Pesqui Bras Odontopediatria Clín Integr. 2020; $20: e 0001$. https://doi.org/10.1590/pboci.2020.093

\begin{abstract}
Objective: To evaluate the effectiveness of an oral health talk aided by a video on improving the awareness of mothers about natal teeth in two rural communities in southwest Nigeria. Material and Methods: A cluster-randomized controlled trial was conducted among 80 mothers in two rural communities in Nigeria, randomized into study and control groups. Baseline information was obtained with a pre-tested interviewer administered questionnaire. The mothers in the study group participated in an oral health education program comprising of a video show on natal teeth in addition to an oral health talk. The control group did not receive any intervention. Post-intervention data was obtained three weeks afterwards. Data collected was analyzed with SPSS using paired t-test, independent t-test and Chi-square test. Results: The sociodemographic characteristics of participants in both groups were similar. The mean knowledge, attitude and practice percentage scores for the study group were $38.9 \pm 26.3 \%$ (pre-intervention) and $73.6 \pm 26.2 \%$ (post-intervention); while for the control group, the values were $43.2 \pm 31.4 \%$ (pre-intervention) and $43.9 \pm$ $32.4 \%$ (post-intervention). The study group, had a $34 \%$ increase in knowledge, attitude and practice percentage score $(\mathrm{CI}=23.7-45.5 ; \mathrm{t}=6.4 ; \mathrm{p}<0.001)$, while the control group, had an increase of $0.7 \%(\mathrm{CI}=-0.7$ 2.2; $\mathrm{t}=1.00 ; \mathrm{p}=0.323)$. Conclusion: An oral health education program comprising of oral health talk and a video about natal teeth improved the awareness of mothers about natal teeth as a normal phenomenon.
\end{abstract}

Keywords: Health Education; Tooth, Deciduous; Oral Health; Instructional Film and Video. 


\section{Introduction}

Natal teeth are teeth erupted at birth, while neonatal teeth are erupted in the first few weeks of life. Natal teeth are rare and it is estimated that they occur in 1:800 to 1:6,000 births [1,2]. Accurate records of natal teeth in Africa are lacking because many cases are underreported [3] and this may be due to the stigma associated with natal teeth [4-6].

Although the literature has revealed that natal teeth have been viewed as a sign of good luck in Europe [7], reports have documented that in Nigeria, children born with natal teeth are viewed with contempt and derision [8,9]. The families of such children are regarded as accursed and affected children stigmatized, as they are believed to possess supernatural powers to make negative pronouncements on people that would happen in the future. Consequently, such children suffer severe humiliation [10], they may be abandoned [11] and in some cases, infanticide is contemplated [8]. This is extremely worrisome.

Various oral health education programs to dispel myths regarding natal teeth have been conducted in Nigeria [8]. Oral health education strategies that have been employed in Nigeria, to solve this problem, are mainly verbal, via posters and traditional songs [8]. However, it appears that these myths and misconceptions linger [10]. These deeply entrenched traditional beliefs are sometimes difficult to dispel as they have been transferred across generations. It then became imperative to use a different approach, which includes a health education video titled "Adunni" in conjunction with a health talk to dispel myths and misconceptions associated with natal teeth, in a rural community deeply entrenched with negative convictions regarding natal teeth.

Adunni [12] is a 28 minute culturally appropriate videotape in the native Yoruba language (spoken in Southwestern Nigeria) with a storyline targeted at the low social class to dispel harmful folklores and misconceptions about natal teeth. We hypothesized that watching this video, coupled with the verbal education talk, will impact positively by improving the participant's knowledge, beliefs and practices regarding natal teeth. The study aimed to evaluate the effectiveness of an oral health talk aided by a video on improving the awareness of mothers about natal teeth in two rural communities in Southwest Nigeria.

\section{Material and Methods}

Study Location

This was a cluster-randomized controlled trial conducted in two rural communities; Igboora and Idere in Ibarapa Central Local Government Area in Oyo State, in the southwestern part of Nigeria. Ibarapa Central Local Government Area is made up of a population of approximately 103,243 people. Igboora is situated 80 kilometers north of Lagos and is the headquarters of Ibarapa Central Local Government [13]. Idere is the adjacent smaller community located 12 kilometers east of Igboora. Igboora has five Primary Health Care Centers (PHCCs), while Idere has two PHCCs serving the communities. In addition, there is a Primary Oral Health Care Center, located at Igboora, which serves the communities in Ibarapa [13]. The later center has an on-going oral health promotion program for the residents of the communities.

\section{Study Participants}

Eighty mothers, half from Igbo-Ora and half from Idere communities, were recruited for the study. The two communities were randomized into the study and control groups using sealed envelopes by an independent research assistant. Twenty participants were selected from each of the two PHCCs in Idere and two of the five PHCCs in Igboora. Consecutive mothers attending the PHCCs were recruited till sample size 
was reached. The inclusion criteria for mothers were: 18 years of age and older, those well versed in the Yoruba language and those that accepted to participate with signed consent form.

\section{Sample Size}

The sample size for the study was calculated using STATA version 14 statistical software. Using an effect size of $50 \%$, power of $80 \%$ at $95 \%$ Confidence Interval (CI) and level of significance of $5 \%$, a sample size of 22 was obtained for the two groups. The sample size was inflated by the Variance Inflation Factor of 1.95 to adjust for clustering effect to give a total of 43 mothers. A minimum of 54 mothers for the two trial groups that is 27 mothers per trial arm was obtained after adjusting for a dropout rate of $20 \%$ (Figure 1).

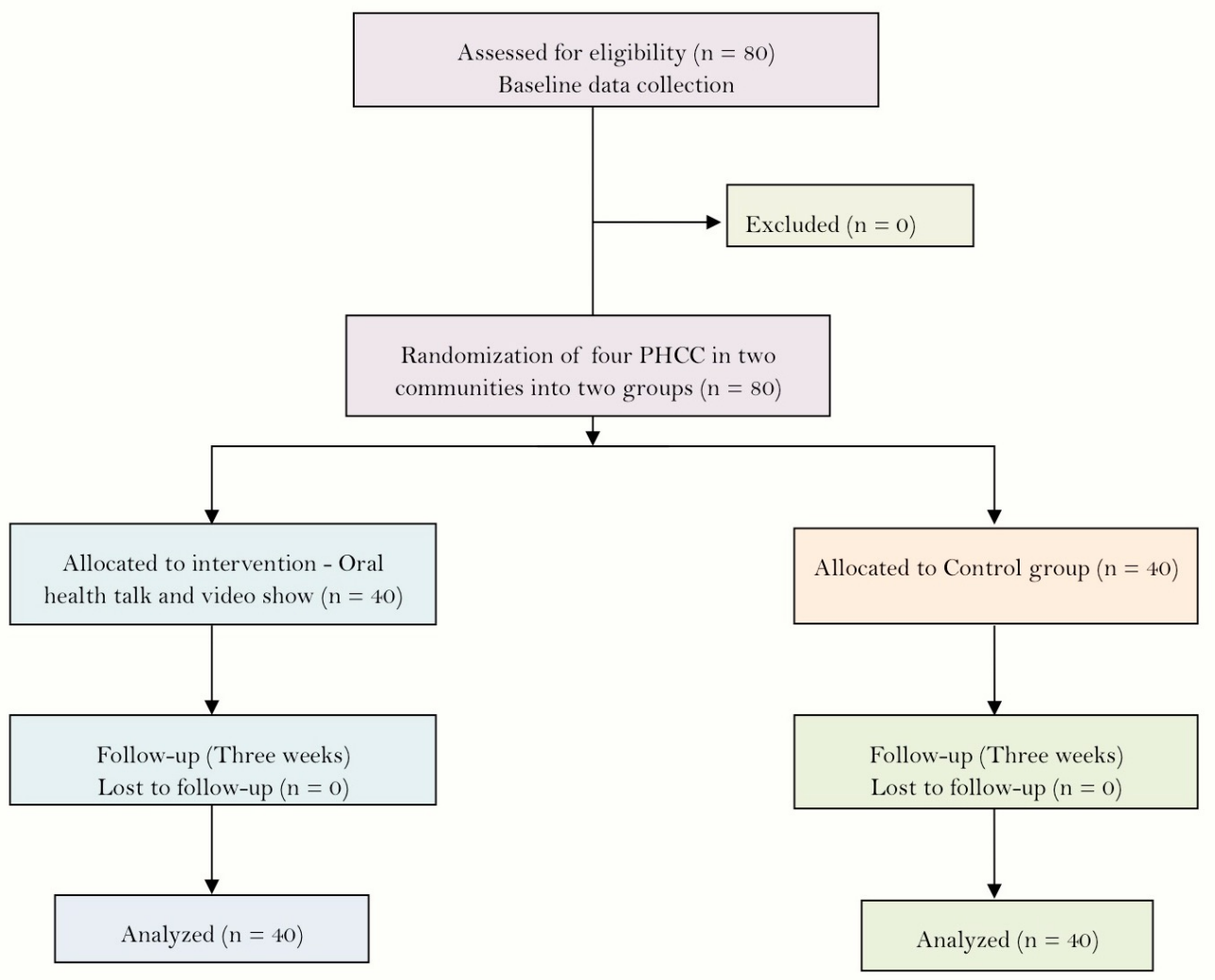

Figure 1. Schematic diagram of the oral health education program on natal teeth.

Study Instrument

A fourteen-item semi-structured interviewer administered questionnaire was used as the data collection tool. The questionnaire was developed by the authors with assistance from relevant literature in English language. It comprised of questions on biodata of the respondents such as the age, educational qualification and occupation of the respondents. There were six statements with options to choose from. Included were questions that assessed their initial reaction if they saw or helped deliver a baby with natal teeth and reasons why children were born with natal teeth. The participants were asked about the possible effect on the family and society, and advice they would give to mothers of affected children. In addition, information was obtained on the advice to be given to pregnant women to forestall this phenomenon and the fate of such children in the community.

The English version of the questionnaire was translated into Yoruba, which is the native language of the community. This was back-translated into English by independent dentists who were fluent in Yoruba and 
English languages and were blinded to the aims and objectives of the study. Very subtle differences were found when the original English version and the back-translated version of the study instrument were compared by members of the research team. The translated questionnaire was pre-tested among 10 women in Igboora community attending a PHCC not included as part of the study centers and thus eventually did not partake in the study. Slight modifications for clarity were effected on the questionnaire based on the responses received before its final administration to the study participants. Data for the study was collected by two trained research assistants who were conversant with the local language of the communities.

\section{Baseline Survey}

Baseline information about knowledge, beliefs and practices related to children born with natal tooth were obtained with the pre-tested interviewer administered questionnaire.

\section{Oral Health Intervention}

After baseline evaluation, mothers in the study group participated in an oral health education program comprising of watching a video "Adunni" on natal teeth in addition to an oral health talk about natal teeth given by a trained dentist for 12 minutes. Adunni is a 28 -minute six scene video about the life of a baby named "Adunn" who was born with a natal tooth and consequently suffered untold stigmatization and humiliation from infancy to adulthood [12]. The video was shot in an environment similar to the setting of the participants, with the same style of dressing and was in their local language, with which they could easily identify. The message in "Adunni" was that natal teeth usually occurred naturally and are not caused by evil spirits or mothers contravening traditional taboos and that the affected child's family was not cursed. Also, it highlighted the fact that children born with natal teeth neither behave strangely nor develop evil spiritual powers and should not be stigmatized, abandoned, hidden or gotten rid of, but rather should be taken to the hospital for examination [12]. The control group did not receive any intervention. Post-intervention data was obtained three weeks after baseline data in the two groups.

\section{Statistical Analysis}

Data obtained were processed with SPSS version 21 and analyzed. Score of 1 was alloted to the correct answers of each item. Data were analyzed with SPSS; means and standard deviations were used to summarize numeric variables. A paired t-test and independent t-test were used to test for associations between continuous variables. Frequencies and proportions were generated for categorical variables. Chi-square statistics was used to determine associations between categorical variables and the level of significance set at $\mathrm{p}<0.05$.

\section{Ethical Considerations}

Ethical approval for the study was granted by the Ethical Review Committee of the Ministry of Health, Oyo State. Furthermore, authorization and permission was also obtained from the heads of the four PHCCs and the head nurses in charge of the centers. Participants gave informed consent before inclusion in the study. After the post-intervention data collection, correct information was provided to all participants about natal teeth and the teething process.

\section{Results}


The mean age of mothers who participated was $28.8 \pm 7.7$ years. Many of the participants, $18(45.0 \%)$ and $17(42.5 \%)$, in the study and control groups respectively had secondary education and 33 (82.5\%) participants each in the study and intervention groups were unskilled workers $(p=0.31)$ (Table 1).

Table 1. Sociodemographic variables of participants in study and control groups.

\begin{tabular}{cccc}
\hline \multicolumn{1}{c}{ Variables } & Study Group & Control Group & p-value \\
\hline Age Group (Years) & $8(66.7)$ & N $(\%)$ & \\
$\leq 20$ & $22(51.2)$ & $4(33.3)$ & 0.30 \\
$21-30$ & $10(40.0)$ & $21(48.8)$ & \\
$>30$ & & $15(60.0)$ & \\
Education & $3(7.5)$ & & \\
No Formal & $8(20.0)$ & $2(5.0)$ & \\
Primary & $18(45.0)$ & $7(17.5)$ & \\
Secondary & $4(10.0)$ & $17(42.5)$ & \\
Post-Secondary & $7(17.5)$ & $6(15.0)$ & \\
University & & $8(20.0)$ & \\
Occupation & $2(5.0)$ & 0.31 \\
Skilled & $33(82.5)$ & $33(82.5)$ & \\
Unskilled & $5(12.5)$ & $7(17.5)$ & \\
Dependents & & & \\
\hline
\end{tabular}

Regarding the respondents' attitude, their reaction, if they saw or helped deliver a baby with teeth, witnessed a $400 \%$ change from the pre- to post-test among the intervention group compared to $30 \%$ change in the control group. This showed marked improvement in the intervention group (Table 2). For participants in the study group, the mean score increased from 0.13 to 0.63 post-intervention, mean difference $=0.5 \pm 0.6 ; \mathrm{t}=$ $4.937(\mathrm{p}<0.001)$. While in the control group, mean score increased from 0.3 to 0.32 , mean difference $0.02 \pm 0.4$ $(\mathrm{p}=0.711)$.

The reasons given for the eruption of natal teeth in babies recorded $90 \%$ correct response in the posttest in comparison to $37.5 \%$ in the pre-test in the study group giving a $140 \%$ improvement. In contrast, pretest and post-test scores for the same item were $55.5 \%$ and $50.0 \%$, respectively, for the control group resulting in $-9.1 \%$ change in the control group. There was a $271.4 \%$ change for the study group and $9.1 \%$ change for the control group concerning correct responses by participants for the perceived effect of natal teeth on the child's family (Table 2).

Table 2. Correct responses pre- and post-study of participants to knowledge, attitude and practice (KAP) questions on natal teeth.

\begin{tabular}{|c|c|c|c|c|c|c|}
\hline \multirow[t]{2}{*}{ Variables } & \multicolumn{3}{|c|}{ Study Group } & \multicolumn{3}{|c|}{ Control Group } \\
\hline & Pre & Post & $\%$ Change & Pre & Post & $\%$ Change \\
\hline Reaction when a baby born with teeth is seen/ delivered & 12.5 & 62.5 & 400.0 & 25.0 & 32.5 & 30.0 \\
\hline Reason why some babies have natal teeth & 37.5 & 90.0 & 140.0 & 55.0 & 50.0 & -9.1 \\
\hline Effect of natal/neonatal teeth on the family & 17.5 & 65.0 & 271.4 & 27.5 & 30.0 & 9.1 \\
\hline Advice to be given to mother of affected child & 32.5 & 52.5 & 61.6 & 30.0 & 30.0 & 0.0 \\
\hline Advice to be given to pregnant women to avoid this & 27.5 & 60.0 & 118.2 & 25.0 & 27.5 & 11.0 \\
\hline Negative effect(s) on the future life of a child with natal teeth & 45.0 & 85.0 & 88.9 & 45.0 & 20.0 & -55.6 \\
\hline
\end{tabular}

Regarding the advice participants will give to the mother of an affected child, the post-test scores in the study group was $52.5 \%$, while the pre-test score was $32.5 \%$, giving a percentage change of $61.6 \%$. In the control group, pre-and post-test scores were $30.0 \%$ each i.e., a $0 \%$ percentage change. 
Concerning positive advice, participants will give to pregnant women to forestall giving birth to children with natal teeth, a $118.2 \%$ change was recorded in the intervention group while a lower value of $11.0 \%$ was noted in the control group.

On inquiry of the possibility of the child's life being negatively affected in the future; $45.0 \%$ and $85.0 \%$ of the participants in the intervention group gave correct responses in the pre and post-intervention evaluation respectively giving an $88.9 \%$ change while pre- and post-scores were $45.0 \%$ and $20.0 \%$ for participants in the control group respectively giving a percentage change of $-55.6 \%$ (Table 2 ).

The mean pre-and post-intervention scores in the study group were $38.9 \pm 26.3 \%$ and $73.6 \% \pm 26.2 \%$ respectively (Table 3). In the control group the mean pre-score and post-score were $43.2 \pm 31.4 \%$ and $43.9 \pm$ $32.4 \%$ respectively. The study group had a 34.6\% increase in knowledge, attitude and practice percentage score $(\mathrm{CI}=23.7-45.5 ; \mathrm{t}=6.4 ; \mathrm{p}<0.001)$, while the control group had an increase of $0.7 \%$ in the mean knowledge, attitude and practice percentage score $(\mathrm{CI}=-0.7-2.2 ; \mathrm{t}=1.00 ; \mathrm{p}=0.323)$.

Table 3. The mean pre- and post- KAP scores for the study and control groups.

\begin{tabular}{|c|c|c|c|c|c|}
\hline Groups & Mean Scores (SD \%) & Mean Difference & CI & $t$ & p-value \\
\hline \multicolumn{6}{|c|}{ Intervention Group } \\
\hline Post & $73.6 \pm 26.2$ & 34.7 & $23.7-45.5$ & 6.4 & $<0.001$ \\
\hline Pre & $38.9 \pm 26.3$ & & & & \\
\hline \multicolumn{6}{|l|}{ Control Group } \\
\hline Post & $43.9 \pm 32.4$ & 0.7 & $0.7-2.2$ & 1.0 & 0.323 \\
\hline Pre & $43.2 \pm 31.4$ & & & & \\
\hline
\end{tabular}

\section{Discussion}

The findings of this study revealed that the health education program was effective in improving the knowledge, beliefs and practices of the participants concerning natal teeth as mean pre-and post-knowledge, attitude and practice scores of the intervention group revealed significant changes in contrast to the control group. There has been no previous study in the literature that reported using a health education video in a local language combined with a health talk to dismiss misconceptions about natal teeth in a rural populace. However, the results are in agreement with other health education interventions using video and health talks targeted at other health problems [14].

When asked - "What will be your initial reaction if you saw/helped deliver a baby born with teeth in the mouth?" the intervention group had a greater percentage improvement of $400.0 \%$ in contrast to $30.0 \%$ among the control group. Reactions to seeing children with natal teeth in the Nigerian environment include being astonished and instantly suspecting that the child is "weird" or "evil" [9,10]. Nigerians have a deep and rich culture and can be very sensitive to cultural issues. Expressing shock and surprise with unkind comments from friends and neighbors will definitely be upsetting for the mother of a neonate. Such negative attitudes are definitely the first step in the life-long mark of stigmatization of the affected child.

Various erroneous etiological factors have been linked with natal teeth [10]. The mother is very often the object of blame as it is alleged that mothers are breaking cultural taboos and being exposed to other demon-possessed children results in birthing a child with natal tooth [8, 10]. In some developing countries, particularly Nigeria, strange and negative phenomena within families are wrongly blamed on the women. Participants showed a $140 \%$ knowledge improvement change in the study group. It is worthy of concern that in the control group, there was further deterioration in knowledge $(-9.1 \%)$ percent change. 
Regarding the effect of a child being born with natal teeth in the family, participants in the intervention group showed a greater degree of improvement in attitude $(271.6 \%)$ in contrast to $30.0 \%$ improvement in the control group. Families of children born with natal teeth in Nigeria are viewed as accursed; natal tooth is considered an abomination, and the affected child is believed to constitute an untold embarrassment to the family [9,10]. The perception by community members causes a lot of fear and anxiety among parents, which sometimes compels them to take harmful and unthinkable dangerous steps to ward off the perceived curses and abominations. This health education strategy succeeded in improving the advice participants in the intervention group would give affected mothers by $61.6 \%$, even though there was no change in the control group. Advice given by respondents in the control group includes hiding the child, getting the tooth extracted with or without sacrifices to reverse the perceived family curses or getting rid of the child. Abandonment and infanticide of children with natal teeth have been reported in the literature [11,15]. In addition, a lot of anecdotal reports occur. The reports include; forceful extraction of "offending" teeth by quacks using crude and unsterile instruments, which may expose affected children to Human Immunodeficiency Virus, hepatitis and bacterial infections.

Similarly, this intervention improved practices regarding the advice the participants will give pregnant mothers as there was $60.0 \%$ improvement in the study group compared to $11.0 \%$ in the control group. It is sometimes erroneously believed in southwestern Nigeria that ingestion of special herbal preparations/concoctions and adhering to all laid down cultural practices for pregnant women would forestall giving birth to babies with natal teeth. The higher rates of improvement noted in the study group may be attributed mainly to the oral health education aided by the video.

Natal teeth are believed to be responsible for bizarre behavior in children in the future [10]. Friends and family get scared and are skeptical of such children as they are traditionally believed to have the ability to place irrevocable curses on people. It is noteworthy that this intervention improved participants' knowledge regarding the future life of affected children with an $88.9 \%$ percentage change, while the control group deteriorated further $(-55.6 \%)$.

Overall, the results of this study revealed effectiveness of the educational intervention and are consistent with some previous interventions using audio, verbal and visual educational strategies [14,16,17]. Part of the success of this educational program could be attributed to the video watched. A major advantage of the use of videos in health education is that they are visually appealing [17,18]. Adunni had a storyline, was shot in a local setting similar to the type the participants reside and had real scenes. The cast, dress, music and dialogue were similar to those of the target population and what the participants could identify with. It has been documented that educational interventions should be customized to meet target groups [19]. People are usually more spellbound with health promotion messages set in a story in their social and cultural backgrounds $[20]$.

Health education can be provided through various means by brochures, leaflets, models and powerpoint presentations [21,22], but this has little influence in rural areas where literacy levels are low such as in our study. The fact that the lecture method of oral health education allowed for a face to face interaction and an avenue for asking questions in addition to watching a video contributed to effectiveness of the intervention. Active engagement of the target audience, as seen in this study, could also have made the intervention acceptable to the participants; this may be a potential cost-effective model for health education in rural areas. 
The next phase of this research will involve showing the video to other vulnerable groups such as grandmothers and mothers-in-law in order to change their beliefs about natal teeth and folklores in general, which can be detrimental to children's oral health.

Some limitations were observed in the conduct of the study. The evaluation period for the intervention was short. It will be desirable to evaluate effectiveness over longer periods. Also, a direct comparison could not be made as there had been no other studies about health education strategies to dispelling myths about natal teeth in a local language. Therefore, a control group, which received no intervention, was used for comparison.

\section{Conclusion}

An oral health education program comprising of oral health talk and a video about natal teeth was able to improve the awareness of mothers about natal teeth as a normal phenomenon.

\section{Authors' Contributions}

\begin{tabular}{|c|c|c|c|}
\hline OOB & (D) 0000-0002-5754-0855 & $\begin{array}{l}\text { Conceptualization, Methodology, Investigation, Formal Analysis, } \\
\text { Original Draft Preparation and Writing - Review and Editing. }\end{array}$ & Writing - \\
\hline FBL & (D) $0000-0002-3193-387 \mathrm{X}$ & $\begin{array}{l}\text { Conceptualization, Methodology, Investigation, Formal Analysis, } \\
\text { Original Draft Preparation and Writing - Review and Editing. }\end{array}$ & Writing - \\
\hline
\end{tabular}

\section{Financial Support}

None.

\section{Conflict of Interest}

The authors declare no conflicts of interest.

\section{References}

[1] Leung AK, Robson WL. Natal teeth: a review. J Natl Med Assoc 2006; 98(2):226-8.

[2] Uzamis M, Olmez S, Ozturk H, Celik H. Clinical and ultrastructural study of natal and neonatal teeth. J Clin Pediatr Dent 1999; 23(3):173-7.

[3] Denloye O, Aderinokun G. Prematurely erupted tooth in the molar region. Niger Dent J 2007; 15(1):49-51. https://doi.org/10.4314/ndj.v15i1.42102

[4] Leung A. Natal teeth. Am J Dis Child 1986; 140: 249-51.

[5] Cunha RF, Boer FA, Torriani DD, Frossard WT. Natal and neonatal teeth: review of the literature. Pediatr Dent 2001; 23(2):158-62.

[6] Zhu J, King D. Natal and neonatal teeth. ASDC J Dent Child 1995; 62(2):123-8.

[7] Gardiner JH. Erupted teeth in the newborn. Proc R Soc Med 1961; 54(6):504-6.

[8] Bankole O, Taiwo J, Nasiru O. Attitude and beliefs of traditional birth attendants to prematurely erupted teeth of infants in urban local government areas in Ibadan, Nigeria. Int Q Community Health Educ 2012; 32(4):355-66. https://doi.org/10.2190/IQ.32.4.g

[9] Oyejide C, Aderinokun G. Beliefs about prematurely erupted teeth in rural yoruba communities, Nigeria. Public Health 1992; 106(6):465-71. https://doi.org/10.1016/s0033-3506(05)80461-5

[10] Bankole O, Oke G. Attitude and beliefs of some nurses in government hospitals in Ibadan, Nigeria to natal/neonatal teeth in infants. Odontostomatol Trop 2013; 36(143):31-8.

[11] Oyapero A, Oyapero O. Abandonment of a neonate with natal tooth. Niger J Clin Med 2014; 6(1):55-60. https://doi.org/10.4314/njcm.v6i1.4

[12] Bankole O, Lawal F, Ibiyemi O. Development of a tool for dispelling myths associated with natal/neonatal teeth:"Adunni" a health education video in a native Nigerian language. Ann Ib Postgrad Med 2017; 15(2):137-41.

[13] Bankole OO, Lawal FB. Teething. Int Q Community Health Educ. 2017; 37(2):99-106. https://doi.org/10.1177/0272684X17701262 
[14] Amin M, Nyachhyon P, Elyasi M, Al-Nuaimi M. Impact of an oral health education workshop on parents' oral health knowledge, attitude, and perceived behavioral control among African immigrants. J Oral Dis 2014; 2014:ID 986745. https://doi.org/10.1155/2014/986745

[15] Bodenhoff J, Gorlin RJ. Natal and neonatal teeth: folklore and fact. Pediatrics 1963; 32(6):1087-93.

[16] Curd P, Ohlmann K, Bush H. Effectiveness of a voluntary nutrition education workshop in a state prison. J Correct Health Care 2013; 19(2):144-50. https://doi.org/10.1177/1078345812474645

[17] Shah N, Mathur VP, Kathuria V, Gupta T. Effectiveness of an educational video in improving oral health knowledge in a hospital setting. Indian J Dent 2016; 7(2):70-5. https://doi.org/10.4103/0975-962X.184646

[18] Joy A, Fujii M. Nutrition videotapes reach low-income WIC audiences. Calif Agr 1995; 49(4):29-31. https://doi.org/10.3733/ca.v049n04p29

[19] Stevenson HC, Davis G. Impact of culturally sensitive AIDS video education on the AIDS risk knowledge of AfricanAmerican adolescents. AIDS Educ Prev 1994; 6(1):40-52.

[20] Mathews C, Guttmacher SJ, Coetzee N, Magwaza S, Stein J, Lombard C, et al. Evaluation of a video based health education strategy to improve sexually transmitted disease partner notification in South Africa. Sex Transm Infect 2002; 78(1):53-7. https://doi.org/10.1136/sti.78.1.53

[21] Brown RM, Canham D, Cureton VY. An oral health education program for Latino immigrant parents. J Sch Nurs 2005; $21(5): 266-71$. https://doi.org/10.1177/10598405050210050401

[22] Gambhir RS, Sohi RK, Nanda T, Sawhney GS, Setia S. Impact of school based oral health education programmes in India: a systematic review. J Clin Diagn Res 2013; 7(12):3107-10. https://doi.org/10.7860/JCDR/2013/6212.3718 